\title{
Relationship between Breast Feeding and Obesity in Children with Low Birth Weight
}

\author{
Mitra Zarrati ${ }^{1}$, Farzad Shidfar ${ }^{1,},{ }^{,}$, Maryam Moradof ${ }^{2}$, Farinaz Nasiri Nejad ${ }^{3}$, Hossein Keyvani \\ ${ }^{4}$, Mohsen Rezaei Hemami ${ }^{5}$, Elham Razmpoosh ${ }^{6}$ \\ ${ }_{1}^{1}$ Department of Nutrition and Biochemistry, Faculty of Health, Tehran University of Medical Sciences, Tehran, IR Iran \\ 2 Department of Exercise Physiology, Islamic Azad University, Tehran, IR Iran \\ 3 Department of Physiology, Medicine Faculty, Tehran University of Medical Sciences, Tehran, IR Iran \\ 4 Department of Virology, Medicine Faculty, Tehran University of Medical Sciences, Tehran, IR Iran \\ 5 Department of Virology, Medicine Faculty, Tehran University of Medical Sciences, Tehran, IR Iran \\ 6 Department of Nutrition, Faculty of Health, Qazvin University of Medical Science, Qazvin, IR Iran \\ ${ }^{*}$ Corresponding author: Farzad Shidfar, Department of Nutrition and Biochemistry, Faculty of Health, Tehran University of Medical Sciences, Tehran, IR Iran, Tel: +98 2188779118, Fax: \\ +98 2188779487, E-mail: f-shidfar@tums.ac.ir.
}

Received: March 09, 2013; Revised: April 25, 2013; Accepted: May 20, 2013

Background: Breast feeding appears to play a role in determining obesity and abdominal obesity during childhood, specifically in children with a history of low birth weight.

Objective: The purpose of this study is to investigate the relation of breast-feeding with either of abdominal obesity and obesity among Iranian school children.

Materials and Methods: A total of 1184 students (625 girls and 559 boys), aged 10 to 13 years old, were selected from 112 governmental elementary schools in Iran. Height, weight, waist circumference and blood pressure were measured using standard instruments and a pretested standardized questionnaire was performed for compiling information about family economics and educational level, firstdegree family history of obesity, history of breast feeding, food pattern and birth weight, as well.

Results: $13.68 \%(\mathrm{n}=160)$ of students had a history of low birth weight, and $26.41 \%$ of them had abdominal obesity. Of all participants, $22.04 \%$ were overweight and 5.32\% were obese which was more prevalent in girls than in boys $(\mathrm{P}=0.03)$. First-degree family history of obesity $(P=0.001)$, excessive gestational weight gain $(P=0.001)$ and birth weight $(P=0.01)$ were significantly correlated with the prevalence of obesity and abdominal obesity during childhood. Moreover the prevalence of abdominal obesity in children with low birth weight was significantly correlated with breast feeding $(\mathrm{P}=0.04)$; But this relation was not significantly about obesity in our participants $(\mathrm{P}=0.9)$. Furthermore duration of breast feeding was significantly and inversely correlated with obesity and abdominal obesity in schoolchildren with low birth weight $(\mathrm{P}=0.01)$.

Conclusions: The results suggest that Breast feeding and its long-term consequences were important factors for preventing metabolic syndrome criteria in childhood and later years of life span. With regard to the increasing prevalence of obesity in children, more research is urgently needed to clarify whether breast feeding have negative consequences for the risk of chronic disease in children, especially in children with low birth weight.

Keywords: Low Birth Weight; Abdominal Obesity; Breast Feeding; Iran

\section{Background}

In many countries, childhood overweight and obesity have extended epidemic proportions (1). Moreover, many complications of obesity such as hypertension and chronic disease are seen in children nowadays (2). Recently endeavors made to understand the risk factors for overweight and obesity; in this regard breast feeding plays an important role. The short term benefits of breast feeding. It provides many health, economical, nutritional and emotional benefits to children as well as improving child growth (3). Increasing evidence (4) demonstrate that, having been breast fed may also have longer term benefits, including prevention of obesity especially before the pubertal onset $(5,6)$. As a result breast feeding and its duration play significant roles in prevention of childhood obesity. In children with low birth weight, consumption of supplement formula is more common, however researchers have shown that, prolonged breast feeding can reduce the risk of obesity during childhood. It might be related to some components exist in breast 
milk such as Grelin, Adipokines and Resistin which influence food intake regulation and lead to balance in energy intake during infancy (7).

Other factors that influence on childhood obesity are first degree family history of obesity, family economic and educational level, child meal patterns, duration of sleeping, physical activity level and birth weight $(8,9)$. On the other hand biological factors, genetics, environmental and socio-economic parameters affect and control the obesity from the early years of life to adulthood (10). Scientists have found that, not only high birth weight children, but also children with low birth weight (LBW), will be obese in their later life $(11,12)$. Children with LBW will gain weight more quickly which is called catch up growth, in order to make up their lack of growth. Thus high rapid weight gain during childhood may lead to an increase in abdominal obesity, insulin resistance and glucose intolerance (13).

Hales and Barker have demonstrated that low birth weight, which is a reflection of nutritional deprivation in uterus (14), might impair the development of the fetal pancreas, (15) and could lead to a predisposition to childhood obesity and non-communicable disease. They have also proposed that, obesity is mainly the result of environmental factors and genetic factors play little or no role in its progress, which is called the "thrifty phenotype" hypothesis (16). Furthermore high rapid weight gain, results in adipogenesis in children with LBW. Align with this, many studies confirmed that children with LBW have more body fat percentage than children with normal birth weight (NBW). Their catch up growth period might cause synthesis of visceral adipose tissue in their body (11) as well as fat accumulation that especially cause abdominal obesity.

\section{Objectives}

The present study attempts to investigate the association of breast feeding and its duration, with obesity and abdominal obesity among elementary school children who had a history of LBW.

\section{Materials and Methods}

A total of 1184 primary school students (625 girls and 550 boys), aged 10 to 13 years old, were selected randomly from 20 governmental elementary schools between 2011 and 2012 in Tehran, Iran. A standardized and validated questionnaire was supplied to mothers for collecting information about family economics and educational level, first degree family history of obesity, children's food pattern, history and duration of breast feeding and birth weight of participants. Information on birth weight of children was collected retrospectively based on newborn demographic data. Ethical approval was provided by the committee of ethics in Tehran University of medical science.

Exclusion criteria included cardio vascular disease, dia- betes mellitus, influenza, renal disease, dental infection and consumption of any drugs and supplements. To validate the questionnaire, it was administered to nutritionist and to evaluate the reliability, it was distributed to 20 schoolchildren who were not participated in the study. Weight was measured using digital scale, without shoes and heavy clothing with a precision of $0.1 \mathrm{Kg}$ and height was measured without shoes to the nearest tenth of a centimeter using a portable stadiometer (Seca model 207 Germany). Likewise waist circumference was measured over skin by an inelastic plastic tape. Abdominal obesity status was classified as a waist circumference at or above 85th percentile of age-and-gender matched children from the National Health and Nutrition Examination survey (NHNES) III cohort (17). Overweight in children was defined as a BMI at or above 85th percentile and lower than the 95th percentile for the children of the same sex and age. Obesity was defined as a BMI above 95th percentile for the children of the same age and sex as well (18). BMI was calculated by dividing weight $(\mathrm{Kg})$ by height square $\left(\mathrm{m}^{2}\right)$. Low birth weight has been defined by the World Health Organization (WHO) as weight at birth of less than 2500 grams (19).

\subsection{Statistical Analyses}

Quantitative variables are presented as mean \pm SD, relative frequency and absolute frequency. SPSS software (version 18.0) was used for statistical analyses. Differences between groups' means were assessed by T-test, and Chisquare was used for comparing proportions. P-value $\leq$ 0.05 considered as statistically significant.

\section{Results}

1184 students, ( 625 girls and 559 boys) aged 10-13 years, were selected from 112 elementary school in, Tehran, Iran. $13.68 \%(n=160)$ of participates were LBW, $26.41 \%$ ( $n$ = 309) were macrosom (more than $4000 \mathrm{gr}$ ) and 59.91\% $(n=701)$ had normal weight at the time of birth. 5.32\% of participants were obese and $22.04 \%$ of them had over weight which were both more common in girls than boys ( $P=0.03$ ). $25.34 \%$ of participants had abdominal obesity ( $\mathrm{ABO}$ ) that was more prevalent in boys compared with girls $(26.48 \%$ vs. $24.32 \%, \mathrm{P}=0.002)$. Our observation showed that, students whose mothers had bachelor's degree or higher were less obese and overweight, although the relationship was not significant $(\mathrm{P}>0.05)$. We also found that, there was a significant relation between father's educational level (Masters of Science and higher degree) with obesity and $\mathrm{ABO}$ in students $(\mathrm{P}=0.02)$. In other words, higher education of participants' fathers was associated with a lower incidence of obesity and ABO. In our study more than half of the fathers and mothers were self-employed and house wives respectively. Our data demonstrated that fathers who were employed and mothers who work outside their homes, had obese children compared to others $(\mathrm{P}=0.03)$. As it is indicated in 
Table 1, birth weight had a significant relationship with BMI, weight, waist circumference and systolic blood pres- sure $(\mathrm{SBP})(\mathrm{P}<0.05)$ but not with other parameters, like height and diastolic blood pressure (DBP) $(\mathrm{P}>0.05)$.

Table 1. Anthropometric Indicators, Systolic Blood Pressure (SBP) and Diastolic Blood Pressure (DBP) in Participates Based on Birth Weight

\begin{tabular}{|c|c|c|c|c|c|}
\hline & \multicolumn{3}{|c|}{ Birth Weight $\left(\right.$ Mean $\left.\pm S^{\mathrm{a}}\right)$} & \multirow[t]{2}{*}{ P-value $^{b}$} & \multirow[t]{2}{*}{ Post $\mathrm{Hoc}^{\mathrm{C}}$} \\
\hline & $\begin{array}{l}\text { Less than } 2500 \\
\text { Grams }\end{array}$ & 2500-4000 Grams & $\begin{array}{l}\text { More than } 4000 \\
\text { Grams }\end{array}$ & & \\
\hline $\mathrm{BMI}^{\mathrm{a}}(\mathrm{Kg} / \mathbf{m} \mathbf{2})$ & $21.91 \pm 5.26$ & $18.78 \pm 3.44$ & $19.48 \pm 3.61$ & 0.029 & $1 \mathrm{vs} 2,2 \mathrm{vs} 3,1 \mathrm{vs} 3$ \\
\hline Weight (Kg) & $47.23 \pm 14.02$ & $40.08 \pm 9.49$ & $42.87 \pm 10.17$ & 0.012 & 1vs2, 2vs3, 1vs3 \\
\hline Height (cm) & $145.93 \pm 7.12$ & $145.49 \pm 6.99$ & $147.72 \pm 7.10$ & 0.341 & 1vs3 2vs3 \\
\hline $\begin{array}{l}\text { Waist Circumfer- } \\
\text { ence }(\mathrm{cm})\end{array}$ & $77.08 \pm 13.33$ & $69.63 \pm 9.63$ & $71.21 \pm 9.85$ & 0.034 & 1vs2, 2vs3, 1vs3 \\
\hline $\begin{array}{l}\text { SBP } \\
(\mathrm{mmHg})^{\mathrm{a}}(\mathrm{mmHg})\end{array}$ & $106.33 \pm 16.14$ & $100.46 \pm 13.15$ & $101.56 \pm 12.87$ & 0.037 & 1vs2, 2vs3, 1vs3 \\
\hline $\begin{array}{l}\text { DBP } \\
(\mathrm{mmHg})^{\mathrm{a}}(\mathrm{mmHg})\end{array}$ & $70.56 \pm 15.23$ & $67.44 \pm 10.40$ & $67.48 \pm 10.01$ & 0.197 & 1vs2, 2vs3, 1vs3 \\
\hline \multicolumn{6}{|c|}{$\begin{array}{l}\text { a Abbreviations: BMI, Body Mass Index; DBP: Diastolic Blood Pressure; SBP, Systolic Blood Pressure; SD, Standard Deviation; } \\
\text { b ANOVA }\end{array}$} \\
\hline
\end{tabular}

\begin{tabular}{|c|c|c|c|c|c|c|c|c|}
\hline & \multicolumn{4}{|c|}{ Obesity } & \multicolumn{4}{|c|}{ Abdominal Obesity (ABO) } \\
\hline & $\begin{array}{l}\text { Normal, Fre- } \\
\text { quency (Relative } \\
\text { Frequency \%) }\end{array}$ & $\begin{array}{l}\text { Obesity, Fre- } \\
\text { quency (Relative } \\
\text { Frequency \%) }\end{array}$ & $\begin{array}{l}\text { Total, Frequen- } \\
\text { cy (Relative } \\
\text { Frequency \%) }\end{array}$ & P-value $^{a}$ & $\begin{array}{l}\text { Normal, Fre- } \\
\text { quency (Relative } \\
\text { Frequency \%) }\end{array}$ & $\begin{array}{l}\text { ABO, Frequen- } \\
\text { cy (Relative } \\
\text { Frequency \%) }\end{array}$ & $\begin{array}{l}\text { Total, Frequen- } \\
\text { cy (Relative } \\
\text { Frequency \%) }\end{array}$ & Pvalue $^{a}$ \\
\hline Gender & & & & 0.19 & & & & 0.39 \\
\hline Girls & $444(51.63)$ & $181(55.86)$ & $625(52.79)$ & & $473(53.51)$ & $152(50.67)$ & $625(52.79)$ & \\
\hline Boys & $416(48.37)$ & $143(44.14)$ & $559(44.14)$ & & $411(46.49)$ & $148(49.33)$ & $432(47.21)$ & \\
\hline $\begin{array}{l}\text { First Degree Fam- } \\
\text { ily Obesity }\end{array}$ & & & & 0.001 & & & & 0.001 \\
\hline Yes & $257(30.06)$ & $175(54.35)$ & $432(36.70)$ & & $274(31.14)$ & $158(53.20)$ & $432(36.70)$ & \\
\hline No & $598(69.94)$ & $147(45.65)$ & $745(63.30)$ & & $606(68.86)$ & $139(46.80)$ & $745(63.30)$ & \\
\hline $\begin{array}{l}\text { Severe Gain } \\
\text { Weight in Preg- } \\
\text { nancy }\end{array}$ & & & & 0.001 & & & & 0.001 \\
\hline Yes & $116(13.49)$ & $77(23.91)$ & $193(16.33)$ & & $118(13.35)$ & $75(25.17)$ & $193(16.33)$ & \\
\hline No & $743(86.40)$ & $245(76.09)$ & $988(83.59)$ & & $766(86.55)$ & $223(74.83)$ & $988(83.59)$ & \\
\hline BreastFeeding & & & & 0.03 & & & & 0.74 \\
\hline Yes & $791(92.08)$ & $293(90.71)$ & $1084(91.71)$ & & $812(92.06)$ & $272(90.67)$ & $1084(91.71)$ & \\
\hline No & $65(7.57)$ & $29(8.98)$ & $94(7.95)$ & & $70(7.63)$ & $27(9.00)$ & $94(7.95)$ & \\
\hline $\begin{array}{l}\text { Duration of Breast } \\
\text { Feeding }\end{array}$ & & & & 0.04 & & & & 0.74 \\
\hline $\begin{array}{l}\text { Less than } 6 \\
\text { months }\end{array}$ & $109(13.46)$ & $46(15.33)$ & $155(13.96)$ & & $113(13.58)$ & $42(15.11)$ & $155(13.96)$ & \\
\hline 6-12 months & $135(16.67)$ & $44(14.67)$ & $179(16.13)$ & & $137(16.47)$ & $42(15.11)$ & $179(16.13)$ & \\
\hline 12-24 months & $566(69.88)$ & $210(70.00)$ & $776(69.91)$ & & $582(69.95)$ & $194(69.78)$ & $776(69.91)$ & \\
\hline Birth Weight & & & & 0.001 & & & & 0.001 \\
\hline$<2500 g r$ & $69(8.11)$ & $91(28.53)$ & $160(13.68)$ & & $80(9.15)$ & $80(27.03)$ & $160(13.68)$ & \\
\hline $2500-4000 \mathrm{gr}$ & $555(65.22)$ & $146(45.77)$ & $701(59.91)$ & & $559(63.96)$ & $142(47.97)$ & $701(59.91)$ & \\
\hline$>4000 \mathrm{gr}$ & $227(26.67)$ & $82(25.71)$ & 30926.41 & & $235(26.89)$ & $74(25.00)$ & $309(26.41)$ & \\
\hline
\end{tabular}

${ }^{\mathrm{a}}$ Chi Square Test 
Based on data demonstrated in Table 2 which illustrates the univariate analyses of predictor variables of obesity and $\mathrm{ABO}$, determined that among participants, only first degree family history of obesity, excessive gestational weight gain and birth weight had significant relation with the prevalence of obesity and $\mathrm{ABO}(\mathrm{P}<$ 0.05). In addition, breast feeding and its duration had significant relation with obesity $(\mathrm{P}=0.03$ and $\mathrm{P}=0.04$ respectively); but they had no meaningful effect on ABO.

$54.35 \%$ of obese and $53.20 \%$ of $\mathrm{ABO}$ participants had first degree family history of obesity $(\mathrm{P}=0.001)$ (Table 2 ), which is more prevalent in girls (40\%) than in boys (33.03\%).

28.53\% and $27.03 \%$ of the children with LBW were obese and had ABO respectively. Among LBW children, normal birth weight and macrosom children, history of LBW, was statistically and significantly more effective on childhood obesity and ABO $(\mathrm{P}<0.05)$. Figure 1 shows that, breast feeding had significant relationship with abdominal obesity $(\mathrm{P}=0.01)$. But there was no significant relation between breast feeding and obesity in participates with low birth weight $(\mathrm{P}=0.9)$.
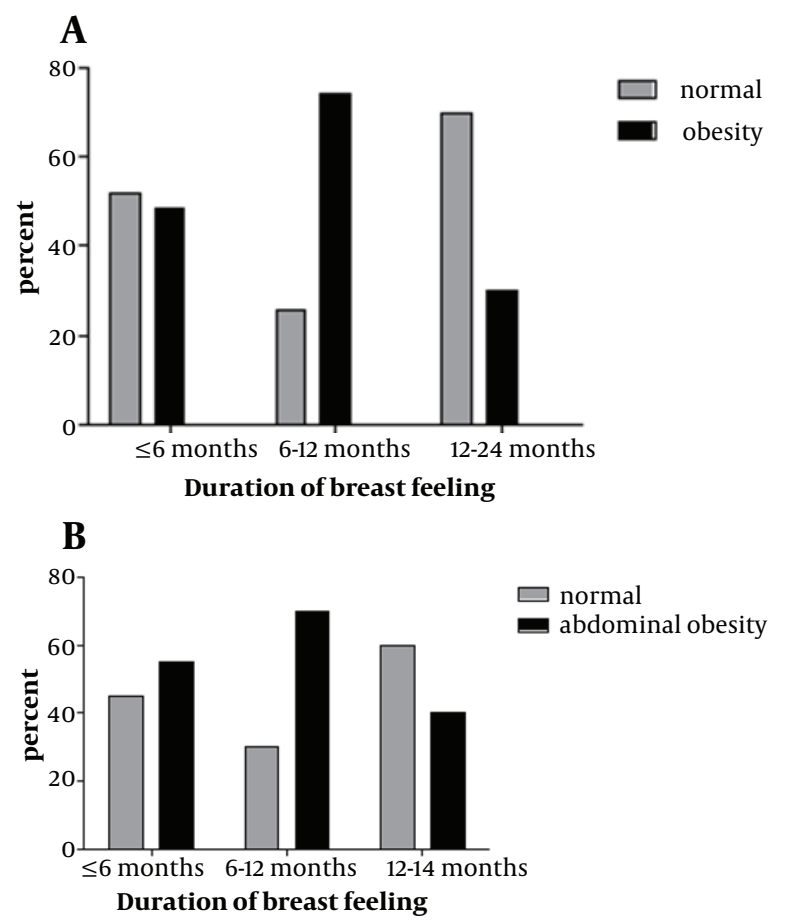

Figure 1. Distribution of BMI (A) and abdominal Obesity (B) by Breast Feeding in Children with Low Birth Weight. ${ }^{*} \mathrm{P}<0.05 ;{ }^{* *} \mathrm{P}>0.05$; BMI: Body Mass Index

Our data reported that duration of breast feeding had significant relationship with childhood obesity and abdominal obesity in LBW group $(\mathrm{P}=0.03$ and $\mathrm{P}=0.002$ respectively). Students with low birth weight, who had been breast fed for 1 to 2 years, showed lower percent of obesity and $\mathrm{ABO}$ during childhood (Figure 2).

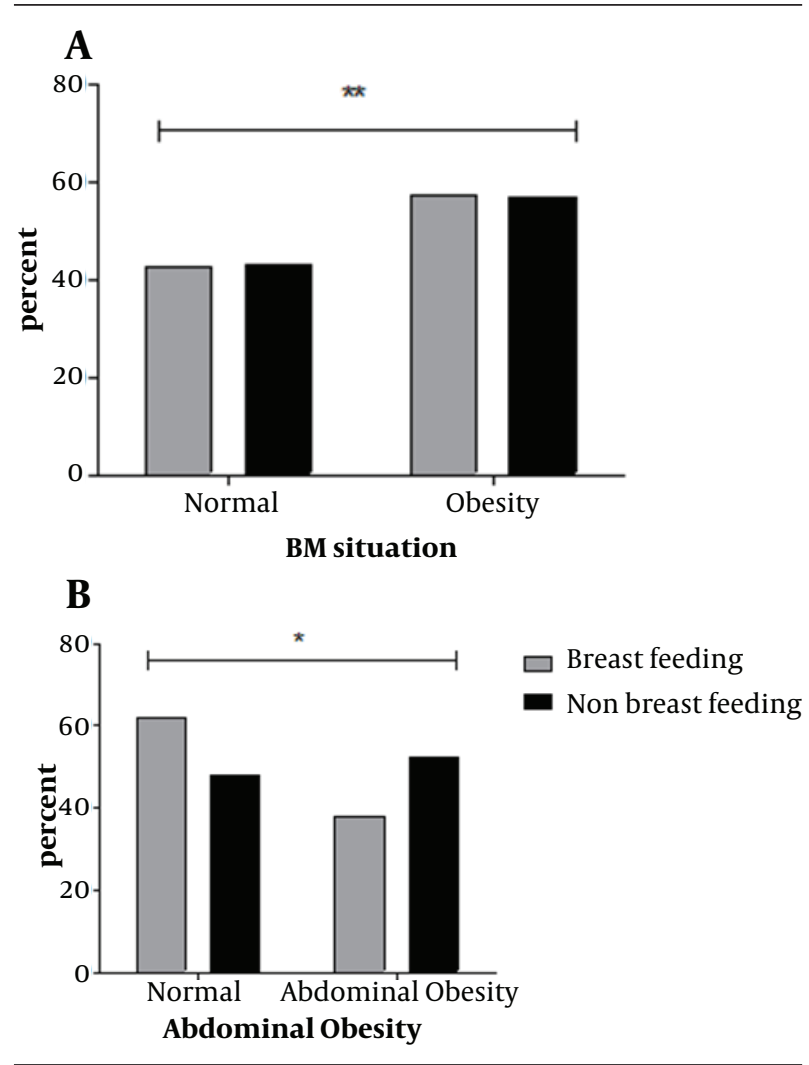

Figure 2. Distribution of Obesity (A) and Abdominal Obesity (B) by Duration of Breast Feeding in Children with Low Birth Weight

\section{Discussions}

High rapid weight gain occurs in LBW children during the first year of their life which might result in later obesity, chronic diseases and early mortality in adulthood. On the other hand, high blood pressure and insulin resistance is also more common in children with a history of LBW (20). Although it is obvious that obesity prevalence varies across populations (21), our findings indicated that, childhood obesity and abdominal obesity are nutritional problems in Iran. Moreover, as there are different cut-off values and references for defining obesity and also different age groups in studies, it is difficult to compare the rate of childhood obesity in various populations. As a result, there is a hypothesis named "thrifty phenotype" which explain the process of change and happen during fetal age and, thus might lead to abnormalities in later life.

Menstrual periods in women during resulted in selection pressures in favor of a thrifty genotype that leads to highly efficient fat storage during periods of abundance (22). In the current climate of food overabundance and sedentary lifestyle, this thrifty genotype suggested to be 
the predictor of disadvantageous metabolic phenotypes. The hypothesis inferred that, adaptation to fetal nutrient-conserving that occurs in response of intrauterine malnutrition, will be overcome by postnatal nutrient abundance, although it could be the cause of chronic diseases and metabolic syndrome in later life (23).

The trend of fetus growth in uterus has been demonstrated for no more than a decade. Furthermore it was observed that, birth weight can be effective on the incidence of chronic problems such as obesity and accumulation of abdominal fat during childhood ( 20 ). The present study suggests that obesity and abdominal obesity were more prevalent in children with a history of LBW compared with other participants. Meanwhile, our study demonstrated that some other involving factors such as first degree family history of obesity, excessive gestational weight gain, duration and history of breast-feeding could be effective on obesity and $\mathrm{ABO}$ during childhood, as well (Table 2). Children with $\mathrm{ABO}$ and without general obesity, have high level of Leptin and Visfatin and low level of Adiponectin which are important risk factors for metabolic syndrome in children ( 24 ).

In the present study, a statistical significant difference in abdominal obesity was seen in breast-fed children compared with formula- or mixed-fed groups. Likewise, we found that, breast-feeding for six months or more was a protective factor against obesity and abdominal obesity in elementary school children which was in accordance with those of Scott and coworkers that was performed in Australia (25). According to our results, breast feeding and particularly its duration, could be effective on obesity and ABO during childhood. Manco et al. (23) conducted a study in Italy which showed that 8 to 9 yearold children who have been breast-fed had significantly greater insulin sensitivity and lower insulin secretion level in comparison with formula-fed group. One of the unique advantages of Manco study was blood sampling assessment, which was not performed in our study. Abdominal fat accumulation is significant in LBW children, due to high level of serum leptin and thus increased insulin resistance which consequently leads to diabetes mellitusr (26).

Present study demonstrated that low prevalence of obesity and $\mathrm{ABO}$ was seen in children who have been breat fed for 1 to 2 years. On the other hand, extended breastfeeding had an important impact on the prevention of chronic disease in children. Many investigations have reported the beneficial effects of history and duration of breastfeeding on various aspects of child health. However Vafa et al. (27) found no significant correlation between these parameters and BMI in children. In a meta-analysis study, conducted by Owen et al. (28), the effect of breast feeding on average BMI was assayed and it was showed that mean BMI was slightly lower among breast-fed subjects, although adjusting for socioeconomic status, maternal BMI, and maternal smoking eliminate the effect.
Data shown in Table 2 demonstrates the relation between $\mathrm{ABO}$ and birth weight and it is in accordance with those of Barker, which was performed among 216 white, girls aged 14 to 16 years old and indicated that low birth weight was an important predictor factor of the prevalence of abdominal obesity in children. Subjects with LBW followed by catch-up-growth in early years of their life had high level of growth hormone during childhood and were more susceptible to abdominal obesity than other groups. In early childhood, obesity and ABO result in insulin resistance and consequently type 2 diabetes mellitus ( 29 - 31 ). It has been established that the prevalence of obesity was more among girls with a history of LBW compared with boys which is similar to our results. Align with these findings; these girls might be at risk of having uterine abnormalities and infertility in their later life. Hence these children need more attention from their birth time and particularly during their childhood ( 32 ).

However our results were not in accordance with those of Peter $S$ that was conducted in Hungary on 1334 subjects aged $7-19$ years old. They reported that the prevalence of obesity was higher among participants with a history of macrosomia than LBW subjects. One might argue that this study contains different age groups comparing to our study, while hormonal alterations especially with genetic attitude could effect on obesity during maturity (33). Moreover one of the unique advantages of the study conducted by Peter and coworkers was measuring the body fat percentage of all participants which was not performed in our study. On the other hand the result of our study was inconsistent with those of Hirchler et al. (34), performed in Buenos among low level socioeconomic status regions. They found no significant relationship between LBW and childhood obesity. On the other hand, no statistical prevalence of obesity and metabolic syndrome was observed among LBW and normal body weight children. By contrast, subjects with high birth weight (HBW), had some components of metabolic syndrome and other which leads to obesity and overweight.

Our study indicated that the average body mass index (BMI) of macrosome subjects was lower than the average body mass index (BMI) of students with LBW (Table 1). On the other hand it was observed that high birth weight was not a risk factor for obesity incidence in early years of life, since other effective factors such as gestational weight gain could affect the outcome. One of the advantages of our study was considering gestational weight gain which was not mentioned in Hirchler 's study. The present study reported that excessive gestational weight gain might cause obesity in offspring which is an independent predictor factor for childhood obesity. We also investigated the association of parental occupational level with either of childhood $\mathrm{ABO}$ and obesity. Mothers with high level of education had beneficial knowledge for controlling nutrition pattern and food intake of their children. In addition high level of parental education was significantly 
inversely associated with BMI in children. The Study of Hirchler ( 34 ) was just restricted to low socioeconomic status regions and hence the outcome showed that LBW children had low BMI in the next years of life.

It has been proved that lower parental educational level led to lower knowledge and hence lower control of food pattern over their children (35). Factors indicating the more prevalence of obesity in high birth weight schoolchildren consist of increasing the amount of fat cells (hypertrophic obesity) in their body and thus more fat accumulation. Though, breast feeding can even diminish the probability of obesity in these children in their later years of life. Meanwhile as history and duration of breast-feeding were not mentioned in Hirchler study, it is not possible to discuss the exact reason of later obesity in high birth weight schoolchildren.

In addition in the CASPIAN study performed by Kelishadi (36) among 21111 students in three different education levels showed that the percentage of obesity and overweight prevalence in Iran was higher in boys than girls, which was in conflict with our results. the large sample size in mentioned study might cause this confliction. However they found that the percentage of $\mathrm{ABO}$ in Iran was higher among boys than girls which were in line with our results. Many studies proved that breast feeding and the length of that have beneficial effect on preventing obesity and non-communicable disease in childhood and adulthood; thus recommending mothers to breast fed their children for at least $6-12$ months, could have important influence on preventing any of them among children. First degree family history of obesity, excessive gestational weight gain and birth weight had significant relationship with the prevalence of obesity and abdominal obesity during childhood. The prevalence of abdominal obesity in students with low birth weight was significantly correlated with breast feeding. In addition as it has been proved, special consideration to LBW newborn children during the process of their growth is necessary. However the trend of fetus growth in uterus has been proved for no more than a decade and more researches is necessary for corroborating the role of LBW on the prevalence of obesity in the next years of life. Furthermore some factors like obesity first degree family history of obesity and excessive gestational weight gain in our study has been found as impressive parameters on obesity and abdominal obesity.

\section{Acknowledgements}

We would like to express our sincere thanks to Dr. Keyvan Virology Research Centre funding for the project and Bita Baradaran, Neda Tizdast and morteza abootorabi as nutritionists and as the project's implementation in schools. None of the authors had a conflict of interest related to the data in the manuscript.

\section{Authors' Contribution}

None declared.

\section{Financial Disclosure}

There is no financial disclosure.

\section{Funding/Support}

There is no funding or supports.

\section{References}

1. de Onis M, Blossner M. Prevalence and trends of overweight among preschool children in developing countries. Am J Clin Nutr. 2000;72(4):1032-9.

2. Freedman DS, Dietz WH, Srinivasan SR, Berenson GS. The relation of overweight to cardiovascular risk factors among children and adolescents: the Bogalusa Heart Study. Pediatrics. 1999;103(6 Pt 1):1175-82.

3. World Health Organization, UNICEF. Protecting, promoting and supporting breast-feeding : the special role of maternity services. Geneva: World Health Organization; 1989.

4. Toschke AM, Vignerova J, Lhotska L, Osancova K, Koletzko B, Von Kries R. Overweight and obesity in 6- to 14-year-old Czech children in 1991: protective effect of breast-feeding. J Pediatr. 2002;141(6):764-9.

5. Hediger Ml Overpeck MDKuczmarski RJRuan W. ASsociation between infant breastfeeding and overweight in young children. JAMA. 2001;285(19):2453-2460.

6. Ravelli AC, van der Meulen JH, Osmond C, Barker DJ, Bleker OP. Infant feeding and adult glucose tolerance, lipid profile, blood pressure, and obesity. Arch Dis Child. 2000;82(3):248-52.

7. Savino F, Fissore MF, Liguori SA, Oggero R. Can hormones contained in mothers' milk account for the beneficial effect of breast-feeding on obesity in children? Clin Endocrinol (Oxf). 2009;71(6):757-65.

8. Del-Rio-Navarro BE, Velazquez-Monroy O, Lara-Esqueda A, Violante-Ortiz R, Fanghanel G, Perez-Sanchez L, et al. Obesity and metabolic risks in children. Arch Med Res. 2008;39(2):215-21.

9. Meng LP, Liu AL, Hu X, Zhang Q, Du SM, Fang HY, et al. Report on childhood obesity in China (10): association of sleep duration with obesity. Biomed Environ Sci. 2012;25(2):133-40.

10. Loaiza S, Coustasse A, Urrutia-Rojas X, Atalah E. Birth weight and obesity risk at first grade in a cohort of Chilean children. Nutr Hosp. 2011;26(1):214-9.

11. Ibanez L, Ong K, Dunger DB, de Zegher F. Early development of adiposity and insulin resistance after catch-up weight gain in small-for-gestational-age children. J Clin Endocrinol Metab. 2006;91(6):2153-8

12. Cottrell EC, Ozanne SE. Early life programming of obesity and metabolic disease. Physiol Behav. 2008;94(1):17-28.

13. Mehrkash M, Kelishadi R, Mohammadian S, Mousavinasab F, Qorbani M, Hashemi ME, et al. Obesity and metabolic syndrome among a representative sample of Iranian adolescents. Southeast Asian J Trop Med Public Health. 2012;43(3):756-63.

14. McCance RA, Widdowson EM. The determinants of growth and form. Proc R Soc Lond B Biol Sci. 1974;185(78):1-17.

15. Swenne I, Bone AJ, Howell SL, Hellerstrom C. Effects of glucose and amino acids on the biosynthesis of DNA and insulin in fetal rat islets maintained in tissue culture. Diabetes. 1980;29(9):68692.

16. Hales CN, Barker DJP. Type 2 (non-insulin-dependent) diabetes mellitus: the thrifty phenotype hypothesis. Diabetologia. 1992;35(7):595-601.

17. McDowell MA, Fryar CD, Ogden CL. Anthropometric reference data for children and adults: United States, 1988-1994. Vital Health 
Stat 11. 2009;(249):1-68.

18. Krebs NF, Himes JH, Jacobson D, Nicklas TA, Guilday P, Styne D. Assessment of child and adolescent overweight and obesity. Pediatrics. 2007;120 Suppl 4:S193-228.

19. World Health Organization. International statistical classification of diseases and related health problems. 10th rev., edition 2008. ed. Geneva: World Health Organization; 2008.

20. Pereira JA, Rondo PH, Lemos JO, Pacheco de Souza JM, Dias RS. The influence of birthweight on arterial blood pressure of children. Clin Nutr. 2010;29(3):337-40.

21. Wang Youfa. Cross-national comparison of childhood obesity: the epidemic and the relationship between obesity and socioeconomic status. Inte J Epidemiol. 2001;30(5):1129-1136.

22. Neel JV. Diabetes mellitus: a "thrifty" genotype rendered detrimental by "progress"? Am J Hum Genet. 1962;14:353-62.

23. Manco M, Alterio A, Bugianesi E, Ciampalini P, Mariani P, Finocchi $\mathrm{M}$, et al. Insulin dynamics of breast- or formula-fed overweight and obese children. JAm Coll Nutr. 2011;30(1):29-38.

24. Ibanez L, Lopez-Bermejo A, Suarez L, Marcos MV, Diaz M, de Zegher F. Visceral adiposity without overweight in children born small for gestational age. J Clin Endocrinol Metab. 2008;93(6):2079-83.

25. Scott JA, Ng SY, Cobiac L. The relationship between breastfeeding and weight status in a national sample of Australian children and adolescents. BMC Public Health. 2012;12:107.

26. Daniels StephenR. Abdominal obesity in prepubertal children.J Pediatr. 2007;150(5):a2

27. Vafa M, Moslehi N, Afshari S, Hossini A, Eshraghian M. Relationship between breastfeeding and obesity in childhood. $J$ Health Popul Nutr. 2012;30(3):303-10.
28. Owen CG, Martin RM, Whincup PH, Davey-Smith G, Gillman MW Cook DG. The effect of breastfeeding on mean body mass index throughout life: a quantitative review of published and unpublished observational evidence. Am J Clin Nutr. 2005;82(6):1298307.

29. Goran Michael I, Ball Geoff DC, Cruz Martha L. Obesity and Risk of Type 2 Diabetes and Cardiovascular Disease in Children and Adolescents. J Clin Endo Metab. 2003;88(4):1417-1427.

30. Batch JA, Baur LA. 3. Management and prevention of obesity and its complications in children and adolescents. Med J Aust. 2005;182(3):130-5.

31. Cruz ML, Bergman RN, Goran MI. Unique effect of visceral fat on insulin sensitivity in obese Hispanic children with a family history of type 2 diabetes. Diabetes Care. 2002;25(9):1631-6.

32. Barker M, Robinson S, Osmond C, Barker DJ. Birth weight and body fat distribution in adolescent girls. Arch Dis Child. 1997;77(5):381-3.

33. Styne DM. Puberty, obesity and ethnicity. Trends Endocrinol Metab. 2004;15(10):472-8.

34. Hirschler V, Bugna J, Roque M, Gilligan T, Gonzalez C. Does low birth weight predict obesity/overweight and metabolic syndrome in elementary school children? Arch Med Res. 2008;39(8):796-802.

35. McCormick DP, Sarpong K, Jordan L, Ray LA, Jain S. Infant obesity: are we ready to make this diagnosis? J Pediatr. 2010;157(1):15-9.

36. Alavian SM, Motlagh ME, Ardalan G, Motaghian M, Davarpanah AH, Kelishadi R. Hypertriglyceridemic waist phenotype and associated lifestyle factors in a national population of youths: CASPIAN Study. J Trop Pediatr. 2008;54(3):169-77. 